\title{
ОСОБЕННОСТИ ВЗАИМОДЕЙСТВИЯ УНИВЕРСИТЕТА И ПРОИЗВОДСТВЕННОГО ПРЕДПРИЯТИЯ ПРИ РЕАЛИЗАЦИИ СОВМЕСТНЫХ ПРОЕКТОВ. ВЗГЛЯД УЧАСТНИКОВ
}

\author{
Монастырный Евгений Александрович1,2,3, \\ e.monastyrny@gmail.com \\ Пудкова Вера Васильевна², \\ vv@tusur.ru \\ Шимко Наталья Валерьевна², \\ nv7191@gmail.com
}

\author{
1Национальный исследовательский Томский политехнический университет, \\ Россия, 634050, г. Томск, пр. Ленина, 30 \\ 2Томский государственный университет систем управления и радиоэлектроники, \\ Россия, 634050, г. Томск, пр. Ленина, 40 \\ 3Томский научный центр СО РАН, \\ Россия, 634055, г. Томск, пр. Академический, 10/4
}

\begin{abstract}
Монастырный Евгений Александрович, доктор экономических наук, профе ссор Школы инженерного предпринимательства Национального исследовательского Томского политехнического университета; профессор кафедры управления инновациями Томского государственного университета систем управления и радиоэлектроники; заведующий лабораторией устойчивого развития социально-экономических систем Томского научного центра СО РАН.
\end{abstract}

Пудкова Вера Васильевна, кандидат экономических наук, ведущий инженер Офиса коммерциализации разработок Томского государственного университета систем управления и радиоэлектроники.

Шимко Наталья Валерьевна, кандидат экономических наук, доцент кафедры экономики Томского государственного университета систем управления и радиоэлектроники.

Актуальность работы определяется необходимостью выстраивания наиболее эффективных взаимоотношений между университетами и производственными предприятиями при поддержке государства для ускорения процессов трансфера научных результатов в промышленность и далее вывода на рынок, тем самым способствуя развитию экономики страны. Цель: анализ взаимодействия университета и производственного предприятия на примере Томского государственного университета систем управления и радиоэлектроники. Для описания экономических показателей финансирования научных проектов в университете на общем фоне экономической ситуации 2011-2018 г2. в Томской области, Сибирском федеральном округе, Российской Федерации использованы открытые данные отчетов о научной деятельности Томского государственного университета систем управления и радиоэлектроники, данные федеральной статистики и ведомственных отчетов. В ходе исследования были проведены опросы с помощью полуструктурированных интервью представителей науки и бизнеса. Методы: эмпирико-теоретические, в частности индукции; методы научного познания, такие как экспертные оценки и анализ. На основе анализа интервью, текущей ситуации и экономических данных разработаны рекомендации, содействующие улучшению и активизации взаимодействий университета и производственного предприятия. 
Ключевые слова: Постановление Правительства № 218, взаимодействие, кооперация, высокотехнологичное производство, индустриальный партнер, производственное предприятие, университет, комплексные проекты.

\section{Актуальность}

Взаимодействие университета и производственного предприятия при реализации совместных проектов, а также взаимодействие трио «университет-бизнес-власть» в последние 20 лет широко обсуждаются в литературе, научных статьях и на конференциях. Особенности научно-технической политики Российской Федерации, в том числе механизмы реализации федеральной целевой программы «Исследования и разработки на период 2013-2020 гг.» и некоторые особенности постановления Правительства № 218 «О мерах государственной поддержки развития кооперации российских высших учебных заведений и организаций, реализующих комплексные проекты по созданию высокотехнологичного производства» от 9 апреля 2010 г. рассмотрены в работе Ю.Н. Андреева [1]. На основе анализа сделаны выводы об уязвимости базовых идей научно-технической политики Российской Федерации и соответствия их современным требованиям. В работе Е.А. Даниловой [2] анализируется современная система научно-производственной кооперации при поддержке государства, являющаяся одним из ключевых инструментов текущей инновационной политики Российской Федерации. Выявлены показатели активности и результативности предприятий и сопровождавших их в конкурсе вузов. Определена региональная иерархия участия предприятий и вузов в данном инструменте инновационного развития. Исследованы особенности механизмов кооперации вузов и предприятий в зависимости от их местоположения: проекты в одном регионе и межрегиональные проекты. Дана общая оценка инструмента научно-производственной кооперации, предложенного постановлением Правительства № 218 (ПП-218), и намечен дальнейший сценарий его применения.

Вопросы эффективности реализации комплексных проектов по ПП-218 и конкретные примеры рассматриваются следующими авторами: А.Б. Пушкаренко, В.В. Аксенов, В.Ю. Бегляков, А.В. Вальтер, А.Б. Ефременков, А.А. Казанцев, В.В. Доценко, Н.Д. Малютин, Е.В. Ташлыкова, А.Б. Петроченков, А.А. Ташкинов [3-5]. В работах описан опыт участия производственных предприятий и университетов в проектах по организации высокотехнологичного производства.

В работе С.С. Кугаевского [6] приводится пример создания условий для мотивации студентов к проведению научно-исследовательских работ при выполнении проектов по ПП-218. Делаются выводы, что только при взаимодействии предприятий и университета при решении реальных производственных задач можно подготовить выпускника вуза к производственной деятельности.

Взаимодействие трио «университет-бизнес-власть» рассматривается в работах как российских [7-13], так и зарубежных авторов [14-18]. Наряду с имеющимися многочисленными проблемами во взаимоотношениях трех факторов отмечается прогресс такого взаимодействия в разных странах и при различных социально-экономических и социально-политических условиях, подчеркивается переплетение интересов и синергетический эффект совместной работы, а также разрабатываются и предлагаются рекомендации по развитию взаимодействия в конкретных условиях на различных стадиях развития определенных инновационных экосистем.

В нашем исследовании рассматриваются три вида взаимодействия университета и производственного предприятия в сфере научно-исследовательских и опытно- 
конструкторских работ (НИОКР), причем два первых осуществляются при поддержке государства:

1) в рамках Постановления Правительства № 218 «О мерах государственной поддержки развития кооперации российских высших учебных заведений и организаций, реализующих комплексные проекты по созданию высокотехнологичного производства» от 9 апреля 2010 г. [19];

2) в рамках Федеральной целевой программы «Исследования и разработки по приоритетным направлениям развития научно-технологического комплекса России на 20142020 годы» (далее - ФЦП) [20];

3) в рамках хозяйственных договоров (финансирование и выполнение научных исследований и разработок из средств российских хозяйствующих субъектов), когда предприятие заказывает НИОКР в университете.

Целью государственной поддержки по ПП-218 является развитие кооперации российских высших учебных заведений, научных учреждений и производственных предприятий, развитие научной и образовательной деятельности в российских вузах, стимулирование использования производственными предприятиями потенциала российских высших учебных заведений и научных учреждений для развития наукоемкого производства и стимулирования инновационной деятельности в российской экономике.

Постановлением предусмотрена возможность выделения субсидий производственным предприятиям сроком от 1 до 3 лет, объёмом финансирования до 100 млн руб. в год для финансирования комплексных проектов организации высокотехнологичного производства, выполняемых совместно производственными предприятиями и высшими учебными заведениями или научными учреждениями. Организация нового высокотехнологичного производства осуществляется за счёт собственных средств предприятия. При этом не менее 20 \% указанных средств должно быть использовано на научно-исследовательские, опытно-конструкторские и технологические работы.

Целью ФЦП является формирование конкурентоспособного и эффективно функционирующего сектора прикладных научных исследований и разработок.

Наиболее часто университеты, научные организации взаимодействуют с ПП по двум направлениям (мероприятиям) ФЦП:

- мероприятие 1.2. Проведение прикладных научных исследований для развития отраслей экономики;

- мероприятие 1.3. Проведение прикладных научных исследований и разработок, направленных на создание продукции и технологий.

По этим направлениям финансирование прикладных научных исследований осуществляется на условиях внебюджетного софинансирования и привлечения к дальнейшему практическому использованию (коммерциализации) их результатов конкретных потребителей результатов работ. Объем привлекаемого внебюджетного софинансирования должен составлять не менее $20 \%$ (для мероприятия 1.2.) или 40 \% (для мероприятия 1.3.) общего объема финансирования для проектов, выполняемых по инициативно сформированной тематике. При этом не менее 20 \% объема привлекаемых внебюджетных средств должно быть затрачено на выполнение прикладных научных исследований по проекту (для мероприятия 1.2.) или на выполнение прикладных научных исследований и экспериментальных разработок по проекту (для мероприятия 1.3.). Поддерживаются проекты, имеющие конкретного потребителя результата, который принимает на себя обязательство полностью или частично обеспечить внебюджетное софинансирование проекта и дальнейшее практическое использование результатов работ (коммерциализацию). 
В процессе взаимодействия университета и производственного предприятия при реализации крупных совместных проектов, поддерживаемых федеральными органами, как правило, возникают проблемы не только «университет - производственное предприятие», но и «университет - Минобрнауки РФ», «производственное предприятие -Минобрнауки РФ», в частности:

- проблемы понимания сотрудниками федеральных и контролирующих органов того факта, что отрицательный результат НИОКР, недостижение заявляемых технических показателей - это результат;

- различие в понимании результата сотрудниками университета, для которых результат - это достижение чего-того нового в теоретических и экспериментальных работах, и сотрудниками производственного предприятия, для которых результат - это продукт, готовый для внедрения в производственный процесс уже сегодня;

- из предыдущего пункта возникает множество аспектов по доведению продукции до «удобоваримого» для производственного предприятия вида;

- проблемы единого понимания (с трех сторон) всех стадий НИОКР и инновационных проектов;

- недостаточное финансирование НИОКР, малое количество источников финансирования инновационных проектов в РЕГИОНАХ (в Москве в последние 3-5 лет появилось много венчурных фондов, в которые предоставляют финансирование на различных условиях. Чтобы из региона получить такое финансирование, необходимо раз в неделю летать в Москву, а на стартовом этапе инновационного проекта, как правило, ни у ученых, ни у предприятий таких средств (ещё раз подчеркнём - в регионах) нет);

- участники проектов сталкиваются с недостатком компетенции сотрудников по узкоспециализированным вопросам: по некоторым техническим направлениям бывает очень сложно найти высококвалифицированного специалиста в близкой досягаемости.

Цель исследования: анализ взаимодействия университета и производственного предприятия на примере ФГБОУ ВО «Томский государственный университет систем управления и радиоэлектроники» (ТУСУР).

Задачи исследования:

1) описание экономических показателей финансирования научных проектов в университете на общем фоне экономической ситуации 2011-2018 гг. в Томской области, Сибирском федеральном округе, Российской Федерации;

2) разработка полуструктурированного интервью и опрос участников крупных проектов, выполняемых совместно университетом и производственным предприятием;

3) разработка рекомендаций по улучшению и активизации взаимодействий университета и производственного предприятия.

\section{Методология проведения исследования}

Для описания экономических показателей финансирования научных проектов в университете на общем фоне экономической ситуации 2011-2018 гг. в Томской области, Сибирском федеральном округе, Российской Федерации использованы открытые данный отчетов о научной деятельности ТУСУРа [21], данные федеральной статистики и ведомственных отчетов.

В ходе исследования были проведены опросы с помощью полуструктурированных интервью представителей науки и бизнеса. Респонденты принимали участие как в проектах, выполняемых при финансовой поддержке по ПП-218 и ФЦП, так и в проектах, которые финансировали только производственные предприятия. Шаблон полуструктурированного интервью содержал шесть разделов: 
1. Взаимодействие «университетское образование - высокотехнологичное производство».

2. Взаимодействие «университетская наука - высокотехнологичное производство».

3. Взаимодействие с соисполнителями (третьими лицами) в рамках совместных проектов по ПП-218 и ФЦП).

4. Проблемы при реализации ПП- 218 и ФЦП.

5. Взаимодействие с потенциальными потребителями.

6. Окружение (экосистема).

Каждый эксперт принимал участие в реализации «крупного» проекта НИОКР, который получил поддержку либо в рамках ПП-218, либо в ФЦП.

$80 \%$ производственных предприятий, сотрудники которых приняли участие в опросе, за последние 5-7 лет заказывали НИОКР в университете непосредственно, минуя финансовую поддержку государства. Однако в этом случае суммы проекта были на порядок меньше и исчислялись не более чем десятками миллионов рублей (не сотни миллионов).

\section{Экономические показатели финансирования научных проектов в университете}

В 2010 г. высокотехнологичные производственные предприятия-партнеры ТУСУРа впервые приняли участие в конкурсе на поддержку совместных проектов по ПП-218. Финансовые данные рассматриваются, начиная с 2009 г. (за год до начала действия ПП-218) [21].

Финансирование научных исследований ТУСУРа представлено на рисунке.



Рисунок. Финансирование научных исследований в ТУсУРе, тыс. .

Figure. Financing of scientific research in TUSUR, thousand rubles

Направления проектов, реализуемых по ПП-218 и ФЦП, в которых участвовал или участвует ТУСУР, представлены в табл. 1. 
Таблища 1. Направления проектов ТУСУРа по ПП-218 и ФЦП

Table 1. Directions of TUSUR projects on Government Decision No. 218 and the Federal Target Program

\begin{tabular}{|l|c|c|}
\hline \multicolumn{1}{|c|}{\begin{tabular}{c}
\multicolumn{1}{|c|}{ Направление проектов } \\
Directions of TUSUR projects
\end{tabular}} & $\begin{array}{c}\text { Количество } \\
\text { Amount }\end{array}$ & $\begin{array}{c}\text { Процентное соотношение, \% } \\
\text { Percentage }\end{array}$ \\
\hline $\begin{array}{l}\text { Приборостроение, связь, электронная компонентная } \\
\text { база }\end{array}$ & 20 & 80 \\
$\begin{array}{l}\text { Professional equipment, telecommunications, electronic } \\
\text { component base }\end{array}$ & 4 & 16 \\
\hline ИТ/IT & 1 & 4 \\
\hline Материаловедение (покрытия)/Material sciences (cover) & & \\
\hline
\end{tabular}

\section{Анализ интервью участников крупных проектов, выполняемых совместно университетом и производственным предприятием}

В ходе исследования были проведены опросы с помощью полуструктурированных интервью представителей науки и бизнеса (шесть человек, 12 проектов), имеющих 3-20летний опыт работы по совместным проектам. В ходе обработки интервью мы старались выявить общие тенденции взаимодействия «университет - производственное предприятие (высокотехнологичное)», однако мнения интервьюируемых оказались настолько профессиональными и глубокими, что мы решили в большей степени представить именно их, лишь слегка структурировав информацию.

Дальнейшее изложение материала ведется в соответствии с разделами полуструктурированного интервью.

\section{Взаимодействие «университетское образование - высокотехнологичное производство»}

Общие высказывания респондентов:

Инициатором взаимодействия являются в двух случаях - «Бизнес». В двух случаях - университет и в одном случае - обоюдное решение руководств.

Цели «взаимодействия университетов и бизнеса»: подготовка кадров для нужд предприятий, создание научно-технических заделов на долгосрочную перспективу. Привлечение дополнительного финансирования в проекты развития. Получение опыта реализации «крупных» проектов, опыта взаимодействия с научной средой, развитие производственных процессов. «Неинтересно реализовать отдельно взятый проект: интересно сотрудничество на долгосрочной основе».

Одно предприятие было организовано выпускниками ТУСУРа, сейчас там работает примерно 50 \% от общего количества сотрудников, во втором - два человека, в третьем - семь, в четвертом - пять.

Преподавательская деятельность представителей бизнеса в университетах. Специалисты двух предприятий время от времени преподают в университетах Томска. Очень неохотно. Причин несколько. Первая - занятость специалистов. У «среднестатистического» разработчика на предприятии до пяти проектов параллельно и более. Второе - сотрудники университета переоценивают способности специалистов реального сектора экономики, особенно это касается учебного процесса. И третье - не найдена эффективная форма привлечения сотрудников индустриального партнера к учебному процессу. Самая оптимальная форма - это совместная работа со студентом (производственная практика) над реальной задачей/проектом. Однако к непосредственно к учебному процессу большая часть партнеров не готова, не в состоянии это сделать. 
Таблища 2. Интересы университета и производственного предприятия Table 2. Motivation for university and industrial enterprise

\begin{tabular}{|l|l|}
\hline \multicolumn{1}{|c|}{$\begin{array}{l}\text { Интерес для университета } \\
\text { Motivation for university }\end{array}$} & \multicolumn{1}{|c|}{$\begin{array}{c}\text { Интерес для производственного предприятия } \\
\text { Motivation for industrial enterprise }\end{array}$} \\
\hline $\begin{array}{l}\text { Финансирование проектов } \\
\text { Additional financing sources }\end{array}$ & $\begin{array}{l}\text { Финансирование проектов, новых разработок } \\
\text { Additional financial sources for projects and developments }\end{array}$ \\
\hline $\begin{array}{l}\text { Подготовка студентов по запросу бизнеса } \\
\text { Трудоустройство выпускников вуза } \\
\text { meaching students for business request Employ- }\end{array}$ & $\begin{array}{l}\text { Подготовка и трудоустройство квалифицированных } \\
\text { специалистов } \\
\text { Тraining and employment of qualified specialists }\end{array}$ \\
\hline $\begin{array}{l}\text { Опыт взаимодействия с бизнесом } \\
\text { Ехреrience in interacting with business }\end{array}$ & $\begin{array}{l}\text { Опыт взаимодействия с научной средой, научными со- } \\
\text { трудниками } \\
\text { Eхреrience in interacting with scientific соттипity and } \\
\text { researchers }\end{array}$ \\
\hline $\begin{array}{l}\text { Узнаваемость университета в бизнес-среде } \\
\text { University гесоgnition in the business area }\end{array}$ & $\begin{array}{l}\text { Развитие и продвижение компании на рынке } \\
\text { Development and promotion of the сотрапу in the market }\end{array}$ \\
\hline
\end{tabular}

Подготовка кадров. Предприятия тем или иным способом стараются готовить кадры для себя через производственные практики, «базовые» (профильные) кафедры, индивидуальные образовательные траектории обучения, разработку по запросу предприятия специальных дисциплин.

В университете реализуется технология группового обучения (далее - ГПО) [22]. Личное мнение одного из экспертов: «Подготовка через ГПО является наиболее перспективным путем подготовки специалистов для конкретного предприятия под конкретный проект». Производственные предприятия берут студентов на производственную практику, но в последние 2-3 года наблюдается очень сильный спад по количеству. Студенты проходят производственную практику и с официальным оформлением и без такового. На двух предприятиях сотрудники инициируют и предлагают студентам проходить практику на базе производства и чтобы выпускная квалификационная работа была по теме направления деятельности производственного предприятия.

В 2010 г. производственный партнер университета при поддержке Роснано разработал магистерскую программу по разработке и производству мультимедийных многопроцессорных систем на кристалле на базе ТУСУРа. Заинтересованность предприятия в этой программе состояла в удовлетворении потребности в подготовке профориентированных кадров по узкой специализации. Узкоспециализированная направленность и незначительные потребности в таких специалистах в отрасли позволили по ней обучиться магистрантам единожды. К тому же недостаток финансирования не позволил её осуществлять на регулярной основе.

Защџтта диссертащий. На одном предприятии защиты кандидатских диссертаций «притянуты за уши», т. к. надо было отчитываться показателями за госфинансирование. На другом предприятии - 2-3 защиты в год - и опять только потому, что имеется такой показатель в проектах с привлечением госфинансирования. «Заставить сотрудника ИП защищать диссертацию на базе разработок, полученных в совместном НИОКР, можно было только, если мама работает в деканате». Лучший вариант: жена, подруга работает в университете и стремится повысить статус партнера, тогда руководитель проекта стимулирует участника через его окружение.

«Защиты не происходят автоматически. Они происходят, потому что нам (тем, кто понимает плюсы взаимодействия «наука-бизнес») это надо: в результате защит создаются новые приборы, новая аппаратура, которая с научной и инженерной точки зрения значима хотя с точки зрения рынка - не востребована». Согласно «правилам игры» 
(2018-2019) «не защита одной кандидатской диссертации» стала «стоить» вузу минус 5 миллионов рублей - через штрафные санкции за неисполнение показателей.

Формализация взаимодействия: у двух томских предприятий имеются подразделения в университете (есть договоры о сотрудничестве). В Москве заведующий базовой кафедрой является сотрудником ИП.

Проблемы: по двум проектам серьезной проблемой стала территориальная удаленность университета и ИП (Москва-Томск).

\section{Взаимодействие «университетская наука - высокотехнологичное производство»}

Инициирование НИОКР. Взаимодействие между бизнесом и ТУСУРом, как правило, осуществляется благодаря личным связям и самим личностям. Влияние личных связей и личностей на совместные проекты 100 \%, личных связей в самом положительном смысле.

Почему предприятия заказывают НИОКР в университете:

- более «свободное» выполнение проекта, т. е. условия менее жесткие, чем государственный оборонный заказ;

- наличие в университете кадров, способных реализовать проект;

- возможность получить продукт, который впоследствии будет производиться;

- во взаимодействии с университетом можно привлечь дополнительное финансирование для новых разработок компании.

НИОКР предприятия заказывают как в рамках господдержки, так и «напрямую» в университете, юридически оформляя как хозяйственный договор на НИОКР.

Количество результатов интеллектуальной деятельности (РИД), созданных на базе совместных проектов, - от 1 до 10 РИД на проект. Патентообладатель - вуз. РИД защищаются, как правило, если имеется требование гранто-/субсидия- дателя в ключевых показателях проекта. Если идет «прямой» заказ от индустриального партнера на НИОКР в университет, РИД без оформления правовых документов передается индустриальному партнеру. В случае выполнения проекта с государственной поддержкой оформляются правовые документы на РИД (патент, свидетельство) и передается на правах отчуждения, исключительной или неисключительной лицензии индустриальному партнеру.

В 90 \% случаях РИД используется внутри предприятия.

«Сейчас условия жесткие: по соглашению с Минобрнауки РФ университет передает интеллектуальную собственность».

Условия передачи интеллектуальной собственности согласовываются между университетом и индустриальным партнером, и в каждом конкретном случае они индивидуальны: первый платеж - от 1000 до миллионов рублей, роялти - от 0 до $5 \%$.

Затраты на НИОКР. Предприятие в сфере ИТ тратит на НИОКР до 30 \% оборотных средств.

Предприятия, производящие приборы, световые элементы и аппаратуру мелкосерийно, тратят на НИОКР - $10 \ldots 15 \%$ своих оборотных средств.

Ожидания/неожиданности проектов: мнения сотрудников университетов и индустриальных партнеров, участвовавших в совместных проектах:

«Айтишники (IT-специалисты - прим. авторов) не всегда следуют тому техническому заданию, которое было согласовано. И бывает достаточно трудно заставить их делать то, что в этом техническом задании прописано. У них все время возникает желание на ходу что-то немного переиграть, «давайте сделаем по-другому» и т. д., и т. п. Это был момент, меня удививший» - мнение сотрудника ООО, заказавшего программное обеспечение в рамках ФЦП. 
«От проекта по ПП-218 ожидали комплексного решения, готового к внедрению, получились разрозненные компоненты, которые до сих пор дорабатываются. Актуальные практические задачи по ФЦП изменились в процессе выполнения проекта за 3 года, но в Техническое задание с Минобрнауки РФ внести изменения, дополнения не удалось. Хотелось бы большей гибкости от министерства».

«Всегда ожидания превышают результат. В первом реализованном крупном проекте были пять направлений, из которых три были успешными. То есть явно с большим знаком плюс. Первый - технология оказалась очень успешной, второй - измерительная техника (удалось сделать) и третий - радиолокация. Вот эти все три направления с момента окончания проекта продолжают развиваться, продукты продаются и, более того, проекты/продукты совершенствуются дальше. По технологиям: были защищены несколько диссертаций, и сотрудники, защитившие диссертации, сейчас занимают ключевые позиции как у индустриального партнера, так и в университете. Сейчас такими проектами занимается уже «третье поколение». Но поколение не по возрасту, а смена. Они такие вот незаметные смены. Появляется новый человек, магистр, и начинает работать по технологии, а затем и продолжает эту работу. Один проект поэтапно перетекает в другой».

Проблемы реализации крупных НИОКР-проектов. Имеется проблема в финансировании совместных НИОКР-проектов, в которых взаимодействуют «наука-бизнесвласть»:

- некорректные финансовые потоки (очень часто в конце года начинается финансирование проекта и за 1-2 месяца надо «потратить» огромные суммы, вместо того, чтобы вдумчиво распределить их на весь проект 26-40 месяцев);

- сложность приобретения дорогого зарубежного оборудования, необходимого для НИОКР, ввиду несовершенства законодательства и нормативно-правовых актов РФ;

- изначально у науки и бизнеса разные цели: ИП интересует продукт, а ученых научные результаты. Бизнес не всегда понимает, что такое наука и зачем она вообще здесь нужна;

- малый бизнес с большой неохотой пишет отчеты. Для крупных компаний, где есть отделы, которые занимаются тем же маркетингом, например какими-то аналитическими изысканиями, участие в отчетности - дело гораздо более простое.

Мнение участников: «Мы наблюдаем печальную деформацию модели взаимодействия «власть-наука-бизнес», деформацию, создаваемую со стороны государства: деньги реально поступают, допустим, в сентябре. И надо за оставшуюся часть года чтото успеть сделать. Понятное дело, что в такой ситуации получится скорее освоить деньги, нежели сделать что-то реальное. Формально это будет соответствовать закону, будет что-то реально сделано, но, благодаря такой деформации, скорее всего, из этого проекта может ничего хорошего не получиться. Идеальная ситуация может быть следующей: в январе нужно получить деньги, сформировать коллектив и начать работать, а отчитаться в декабре. Таким образом: сентябрь-октябрь - подача заявки; не позже 30 января - деньги на счете победившей организации; сдача отчета - 30 декабря; его проверка Министерством - январь; 5 февраля - деньги на счете организации, продолжающей реализацию проекта.

Мы понимаем, что будут реальные компании, у которых основной интерес - получить деньги, «попилить», формально отчитаться и дальше жить долго и счастливо. А есть компании, в которых люди хотят что-то сделать, реализовать, внедрить в производство. И компания, которая реально что-то хочет сделать должна быть независима от внешних условий, которые создаст или не создаст государство. Компании второго типа 
(«грантоежки-пилильщики») тоже должны быть, ибо они создают «массу», из которой в последствии появляется что-то стоящее».

\section{Взаимодействие с соисполнителями (третьими лицами) в рамках совместных проектов по ПП-218 и ФЦП}

Когда взаимодействие необходимо по условиям конкурса, университеты и ИП привлекают соисполнителей. Уговаривать соисполнителей удается по-разному. Например, в одном проекте попытка привлечения НИИ к проекту удалась с третьего раза, т. к. в НИИ поступил заказ, который НИИ не может сделать, а втроем (университет - ИП НИИ) получилось выполнить заказ. ИП взаимодействовал с НИИ раньше, и руководство НИИ, понимая, что вот этот заказ нужно сначала выполнить как НИР, пошло на взаимодействие с вузом и ИП. В итоге университет делает НИР, НИИ параллельно делает ОКР, ИП - конечный продукт. «И это лучший вариант вообще», - говорит эксперт.

Мнение другого респондента: «Все проблемы в рамках такого взаимодействия решаемы, потому что это проекты не нулевого уровня».

\section{Проблемы при реализации ПП-218 и ФЦП}

Респонденты отметили следующие особенности внутри реализации ПП-218:

- запаздывание финансирования - это «самый окаянный вопрос»;

- в целом создали и проверили ряд технических решений, совершили ошибки, научились, идем дальше;

- 2/3 проектов были бы реализованы без поддержки государственных программ.

\section{Взаимодействие с потенциальными потребителями}

Два респондента отметили: «Маркетинговые исследования рынка по оценке спроса со стороны потенциального потребителя до начала реализации проектов проводятся обязательно, всегда. Это требование конкурсной документации».

Респондент 3: «Потенциальных потребителей (предприятия, лаборатории, вузы) ищет ИП и держит с ними хорошую связь».

Респондент 4: «Выходим на потребителей на выставках, через статьи, конференции, форумы. Пока у тебя прямых человеческих контактов не будет, маловероятно, что будет сделка.

Раньше эффективность сайтов компании была больше. Сейчас, благодаря тому, что развиваются социальные сети, напрямую на сайт приходит меньше. Необходимо проявлять активность, чтобы заинтересовать кого-то. Используем LinkedIn, Facebook, BКонтакте. Еще есть несколько тематических форумов узкоспециализированных (они еще существуют, несмотря на то, что соцсети развиваются), где также размещаем информацию».

\section{Окружение (экосистема)}

Респондент 1. Мнение университета: «Нужны ли кластеры, ассоциации, поддержка региональных властей? Сложный политический вопрос. Я думаю, что роль областной власти минимальная. Я с позиции вуза говорю. Минимальное участие. Я думаю, власть не должна вмешиваться в науку вообще. Кроме раздачи премий. Это мы с удовольствием принимаем. Хоть и мало мне заплатили, но приятно. Науку нужно поддерживать прежде всего морально. Материально они не могут же». 
Респондент 2. Мнение бизнеса: «Конечно, это все (администрация Томской области, Торгово-промышленная палата Томской области (ТТПП), кластеры) помогает. Другое дело, что здесь за вас-то никто ничего не сделает. Они могут организовать поездку. Поедешь, тебе одному там страшно, сложно прийти в какую-нибудь компанию, постучаться в дверь и зайти. Благодаря ТТПП или администрации организовываются встречи на высшем уровне, куда приглашаются крупные российские или зарубежные компании. Но для того, чтобы компании с тобой стали говорить, нужно заранее с ними повзаимодействовать: объявить, что ты приезжаешь на эту встречу, рассказать о продукте, спланировать личные контакты c right person. Для того чтобы это работало, нужен большой пласт подготовительной работы перед поездкой/встречей, желательно за несколько месяцев.

Респондент 3. Бизнес, Москва: «Необходимость во взаимодействии предприятия с окружением (властью, кластерами, организациями инновационной экосистемы) имеется. Для нас это необходимо, т. к. предприятие работает в сфере ЖКХ, которая регулируется законодательными и нормативными актами».

Респондент 4. Университет: «ТТПП и власть могут поддерживать проекты по взаимодействию университета и бизнеса, но делают это как-то избирательно... Администрация области стала часто передавать проект (и финансирование) от инициатора к вузу-фавориту, у которого, к сожалению, не хватает компетенций качественно реализовать проект».

\section{Особые мнения}

Респондент 1: «Особенность финансирования некоторых разработок на государственном уровне: первоначально финансирование отдается московским вузам/организациям, и, когда у них что-то не получается, - эти организации «сбрасывают» работу на периферию, в частности на АО в сфере связи, позиционирующееся в Томске. Предприятие лихорадочно осуществляет ОКР «обрезанную» или запускает прямо в производство существующие системы. В итоге для предприятия идет оплата небольшими деньгами или отложенная оплата. Потому что система такова, что деньги можешь получить тогда, когда сдашь всю продукцию. Но при этом страдают контрагенты, потому что они делают мелкие работы, а возможности получить авансовое финансирование нет. В итоге зарплата и интерес резко падают, время реализации увеличивается.

Основной исполнитель проекта, выигравший финансирование и находящейся в Москве, может иметь даже не все компетенции и все равно берется. Расчет идет на то, что за время реализации проекта эти компетенции появятся. Но, как показывает практика, не появляются. Деваться московской фирме некуда, и тогда основной исполнитель проекта задачи передает на периферию соисполнителю с накопленными компетенциями, если они отвечают этому запросу. Уговаривают хорошо, потому что сделать некоторые вещи они просто не могут.

Почему напрямую не выдать деньги на периферию? Вот когда получают деньги, они рассчитывают, что они за это время научатся. Но за это время у них не получается приобрести необходимые компетенции. И такие ситуации начинают превращаться в систему».

Респондент 2: «Имеется следующая проблема. Бизнес/конкуренты не покупают топологию - покупают человека. Например, в схеме один параметр поменяли, всю топологию надо пересчитывать; далее запускать в пробную серию и измерять параметры, и только после этого становится понятным, правильно ли подобрали параметры и сделали топологию. Выгоднее «купить» человека, чем заказать разработку топологии. Переманивают человека - проектировщика, который и проектирует». 


\section{Рекомендации по улучшению и активизации взаимодействий университета и производственного предприятия}

Проанализировав интервью респондентов, принимавших и принимающих участие в совместных крупных проектах, мы выявили следующие особенности:

1) имеется специфика при реализации комплексных проектов: финансовые потоки и документоведение тормозят реализацию бизнес-процессов предприятий реального сектора экономики;

2) и наука, и бизнес способны подстраиваться под те условия, которые создает власть;

3) привлечение федерального финансирования интересно и «науке» - университетам, и «бизнесу» - производственным предприятиям.

На основе анализа экономических данных, анализа интервью и текущей ситуации разработаны рекомендации, содействующие улучшению и активизации взаимодействий университета и производственного предприятия:

1) разработка и проведения обучающих семинаров для бизнеса по вопросам работы с федеральными ресурсами и кооперации с университетами;

2) разработка и проведения обучающих семинаров для университетов по вопросам работы с федеральными ресурсами и кооперации с бизнесом;

3) навыки переговоров с производственными предприятиями необходимо совершенствовать. Для желающих довести свой научный результат до рыночного продукта необходимо создавать широчайший спектр возможностей внутри университета, обозначать и расширять пути развития для кооперации с производственными предприятиями.

Исследование выполнено при финансовой поддержке РФФИ в рамках научно-исследовательского проекта «Исследование процессов интеграции научно-исследовательских институтов, университетов и высокотехнологичных предприятий на примере научно-образовательного кластера Томской области», проект № 18-010-00917a.

\section{СПИСОК ЛИТЕРАТУРЫ}

1. Андреев Ю.Н. Анализ идеологии научно-технической политики // Экономика, социология и право. 2016. - № 11. - С. 7-15.

2. Данилова Е.А. Инновационный инструмент государственной поддержки научно-производственной кооперации: тематический и региональный срезы // Инновации. - 2013. - № 10. - С. 41-50.

3. Пушкаренко А.Б. О реализации томскими вузами с промышленными партнерами комплексных проектов, связанных с созданием высокотехнологичных производств // Инновации. - 2016. - № 2. - С. 3638.

4. Опыт участия Юргинского технологического института (филиала) НИ ТПУ в проекте по организации высокотехнологичного производства (ППРФ № 218) / В.В. Аксенов, В.Ю. Бегляков, А.В. Вальтер, А.Б. Ефременков, А.А. Казанцев // Технологии и материалы. - 2016. - № 2. - С. 10-17.

5. Доценко В.В., Малютин Н.Д. Разработки аппаратуры радиолокации, приборостроения и электронной компонентной базы СВЧ: основные результаты выполнения комплексных проектов НИИ систем электрической связи и АО «НПФ "Микран"» // Доклады ТУСУР. - 2017. - Т. 20. - № 3. - С. $79-85$.

6. Кугаевский С.С. Проектное обучение студентов и научно-исследовательская деятельность вуза // Инженерное образование. - 2017. - № 22. - С. 130-134.

7. Предпринимательский исследовательский университет как драйвер региональной экономики / Ю.А. Шурыгин, Л.А. Боков, А.Ф. Уваров, А.А. Шелупанов // Вузы - региональной экономике: сборник докладов отчетной научно-практической конференции; под редакцией Е.А. Панасенко, С.В. Ефимова. - Томск, Изд-во ТПУ, 2014. - С. 70-71.

8. Уваров А.Ф. Эффект 3D. Трехмерные синергетические модели пользы как инструмент исследования моделей «Тройная спираль» // Креативная экономика. - 2011. - № 1. - С. 56-59.

9. Uvarov A., Perevodchikov E. The entrepreneurial university in Russia. From idea to reality // Procedia Social and Behavioral Sciences. - 2012. - V. 52. - P. 45-51. 
10. Pavlova I., Burenina M. University-industry cooperation in the context of the regional innovation system in Russia: a case of the Tomsk region // Journal of Eastern Europe Research in Business and Economics - 2016. DOI: $10.5171 / 2016.623415$

11. Гуляев П.В., Егоров Н.Е., Николаев М.В. Проектно-ориентированное управление наукой и образованием в рамках партнерских взаимоотношений «университет-государство-бизнес» // Международный журнал экспериментального образования. - 2014. - № 11-1. - С. 30-37.

12. Павлова И.А. Оценка результативности взаимодействия «университет-бизнес» на примере кластера «Информационные технологии и электроника Томской области» // Современное образование: практико-ориентированные технологии подготовки инженерных кадров: Материалы международной научно-методической конференции. - Томск, 2015. - С. 195-196.

13. Тезяева А.С., Иволгина Н.В. Модель «университет-бизнес-государство» как ключевой элемент развития национальной экономики знаний» // Публичные и частные финансы в инновационной экономике: Материалы международной научно-практической интернет-конференции. - М., 2017. - С. 231-237.

14. Clark B.R. Creating entrepreneurial universities: organizational pathways of transformation. - Bingley: Emerald Publishing, 2001. - 180 p.

15. Etzkowitz H. The Triple Helix: university-industry-government innovation in action. - New York; London: Routledge, 2008. - $176 \mathrm{p}$.

16. The measurement of synergy in innovation systems: redundancy generation in a Triple Helix of universityindustry-government relations / L. Leydesdorff, H. Etzkowitz, I. Ivanova, M. Meyer // Handbook of Science and Technology Indicators / Eds. W. Glänzel, H. Moed, U. Schmoch, M. Thelwall. - Cham: Springer, 2019. P. 421-443.

17. Souzanchi Kashani E., Zarghami H.R. The dynamics of university-industry-government relationships in nanoscience: investigating the Triple-Helix differences between Iran and Switzerland // Technology Analysis and Strategic Management - 2019. - № 31 (7). - P. 817-832.

18. Keerati-Angkoon K., Pichyangkura R. The Triple Helix model: university-industry-governments linkage webbased application recommendation systems for emerging commercial-base research // 4th International Conference on Computer and Technology Applications, ICCTA 2018. - Istanbul, Turkey, 2018. - P. 101-105.

19. Об утверждении правил предоставления субсидий на развитие кооперации российских образовательных организаций высшего образования, государственных научных учреждений и организаций реального сектора экономики в целях реализации комплексных проектов по созданию высокотехнологичных производств в рамках подпрограммы «Инфраструктура научной, научно-технической и инновационной деятельности» государственной программы Российской Федерации «Научно-технологическое развитие Российской Федерации»: постановление Правительства РФ от 09.04.2010 № 218 (ред. от 21.06.2019). URL: http://p218.ru/images/2019/pp218n.pdf (дата обращения 20.11.2019).

20. О Федеральной целевой программе «Исследования и разработки по приоритетным направлениям развития научно-технологического комплекса России на 2014-2020 годы»: постановление Правительства РФ от 21.05.2013 № 426. URL: http://fcpir.ru/upload/medialibrary/332/tekst-programmy.pdf (дата обращения 10.11.2019).

21. Научное управление // Томский государственный университет систем управления и радиоэлектроники. URL: https://tusur.ru/ru/o-tusure/struktura-i-organy-upravleniya/departament-nauki-iinnovatsiy/nauchnoe-upravlenie\#otchjoty_o_nauchnoj_dejatelnosti/ (дата обращения 20.11.2019).

22. Инновационные образовательные технологии // Томский государственный университет систем управления и радиоэлектроники. URL: https://tusur.ru/ru/obrazovanie/innovatsionnye-obrazovatelnyetehnologii (дата обращения 20.11.2019).

Поступила 25.11.2019 г. 
UDC 005.42:378.4:334.7

\title{
SPECIAL ASPECTS OF UNIVERSITY-INDUSTRY INTERACTION IN THE JOINT PROJECTS. PARTICIPANT'S VIEW
}

\author{
Monastyrny Evgeny Alexandrovich1,2,3 \\ e.monastyrny@gmail.com
}

Pudkova Vera Vasilievna ${ }^{2}$

vv@tusur.ru

Shimko Natalya Valerievna²
nv7191@gmail.com

1National Research Tomsk Polytechnic University, 30, Lenin avenue, Tomsk, 634050, Russia.

2Tomsk State University of Control Systems and Radio Electronics, 40, Lenin avenue, Tomsk, 634050, Russia.

3Tomsk Scientific Center SB RAS, 10/4, Akademichesky avenue, Tomsk, 634055, Russia.

Evgeny A. Monastyrny, Dr. Sc., professor, National Research Tomsk Polytechnic University; professor, Tomsk State University of Control Systems and Radio Electronics; head of the laboratory for sustainable development of socio-economic systems, Tomsk Scientific Center, SB RAS.

Vera V. Pudkova, Cand. Sc., leading engineer, Tomsk State University of Control Systems and Radioelectronics.

Natalya V. Shimko, Cand. Sc., associate professor, Tomsk State University of Control Systems and Radio Electronics.

The relevance of the work is determined by the need to build the most effective relationship between universities and industrial enterprises with the support of the state to accelerate the transfer of scientific results in industry and further on the market, thereby contributing to the development of the country's economy. The aim of the research is the analysis of interaction between university and industrial enterprise on the example of Tomsk State University of Control Systems and Radioelectronics. The data from federal statistics and departmental reports are used for description of the general background of the economic situation in 2011-2018 in the Tomsk region, the Siberian Federal Area, the Russian Federation. The open reports on the scientific activities of Tomsk State University of Control Systems and Radioelectronics were used as well. The surveys were conducted with the help of semi-structured interviews with representatives of science and business. Methods: empirical-theoretical, in particular: induction; scientific knowledge method such as expert estimation and analysis. Based on the analysis of economic data, analysis of interviews and the current situation the authors have developed the recommendations. They have potential to contribute for improving and enhancing the interaction between the university and the industrial enterprise.

Key words: Government Decree 218, interaction, cooperation, high-tech production, industrial partner, enterprise, university, science-business projects.

The study was carried out with the financial support of the Russian Federal Property Fund in the framework of the research project «Study of the integration processes of research institutes, universities and high-tech enterprises using the example of the scientific and educational cluster of the Tomsk region», project No. 18-010-00917a. 


\section{REFERENCES}

1. Andreev Yu.N. Analysis of the ideology of science and technology policy. Ekonomika, sotsiologiya i pravo, 2016, no. 11, pp. 7-15. In Rus.

2. Danilova E.A. An innovative instrument of state support for scientific and industrial cooperation: thematic and regional sections. Innovations, 2013, no. 10, pp. 41-50. In Rus.

3. Pushkarenko A.B. On the implementation of Tomsk universities with industrial partners of complex projects related to the creation of high-tech industries]. Innovations, 2016, no. 2, pp. 36-38. In Rus.

4. Aksenov V.V., Beglyakov V.Yu., Walter A.V., Efremenkov A.B., Kazantsev A.A. Experience in the participation of the Yurga Technological Institute (branch) of NI TPU in a project on the organization of high-tech production (PPRF No. 218)]. Tekhnologii i materialy, 2016, no. 2, pp. 10-17. In Rus.

5. Dotsenko V.V., Malyutin N.D. Development of radar equipment, instrumentation and electronic component base microwave: the main results of the comprehensive projects of the Research Institute of Electric Communication Systems and JSC "NPF" «Mikran». Proceedings of Tomsk State University of Control Systems and Radioelectronics, 2017, vol. 20, no. 3, pp. 79-85. In Rus.

6. Kugaevskiy S.S. Student Design and Research. Engineering Education, 2017, no. 22, pp. 130-134. In Rus.

7. Shurygin Yu.A., Bokov L.A., Uvarov A.F., Shelupanov A.A. Predprinimatelskiy issledovatelskiy universitet kak drayver regionalnoy ekonomiki [Entrepreneurial Research University as a driver of regional economics]. Sbornik dokladov otchetnoy nauchno-prakticheskoy konferentsii. Vuzy-regionalnoy ekonomike [Universities for regional economy. Collection of reports of the reporting scientific-practical conference]. Eds. E.A. Panasenko, S.V. Efimova. Tomsk, TPU Publ., 2014. pp. 70-71.

8. Uvarov A.F. Three-dimensional synergetic benefit models as a tool for researching the Triple Helix models. Creative economy, 2011, no. 1, pp. 56-59. In Rus.

9. Uvarov A., Perevodchikov E. The entrepreneurial university in Russia. From idea to reality. Procedia - Social and Behavioral Sciences, 2012, vol. 52, pp. 45-51.

10. Pavlova I., Burenina M. University-industry cooperation in the context of the regional innovation system in Russia: A case of the Tomsk region. Journal of Eastern Europe Research in Business and Economics, 2016. DOI: $10.5171 / 2016.623415$

11. Gulyaev P.V., Egorov N.E., Nikolaev M.V. Project-oriented management of science and education in the framework of partnerships «university-state-business». Mezhdunarodny zhurnal eksperimentalnogo obrazovaniya, 2014, no. 11-1, pp. 30-37. In Rus.

12. Pavlova I.A. Otsenka rezultativnosti vzaimodeystviya «universitet-biznes» na primere klastera «Informatsionnye tekhnologii i elektronika Tomskoy oblasti» [Evaluation of the effectiveness of the interaction «university-business» on the example of the cluster «Information Technology and Electronics of the Tomsk Region»]. Materialy mezhdunarodnoy nauchno-metodicheskoy konferentsii. Sovremennoe obrazovanie: praktiko-orientirovannye tekhnologii podgotovki inzhenernyh kadrov [Modern education: practice-oriented technologies for training engineering personnel. Materials of the international scientific and methodological conference]. Tomsk, 2015, pp. 195-196.

13. Tezyaeva A.S., Ivolgina N.V. Model «universitet-biznes-gosudarstvo» kak klyuchevoy element razvitiya natsionalnoy ekonomiki znaniy [The model «university-business-state» as a key element in the development of the national knowledge economy]. Materialy mezhdunarodnoy nauchno-prakticheskoy internet-konferentsii. Publichnye i chastnye finansy v innovatsionnoy ekonomike [Public and private finance in an innovative economy. Materials of the international scientific and practical Internet conference]. Moscow, 2017. pp. 231237.

14. Clark B.R. Creating entrepreneurial universities: organizational pathways of transformation., Bingley, Emerald Publishing, 2001. 180 p.

15. Etzkowitz H. The Triple Helix: university-industry-government innovation in action. New York, London, Routledge, 2008. $176 \mathrm{p}$.

16. Leydesdorff L., Etzkowitz H., Ivanova I., Meyer M. The measurement of synergy in innovation systems: redundancy generation in a Triple Helix of university-industry-government relations. Handbook of Science and Technology Indicators. Eds. W. Glänzel, H. Moed, U. Schmoch, M. Thelwall. Cham, Springer, 2019. pp. 421443.

17. Souzanchi Kashani E., Zarghami H.R. The dynamics of university-industry-government relationships in Nanoscience: investigating the Triple-Helix differences between Iran and Switzerland. Technology Analysis and Strategic Management, 2019, no. 31 (7), pp. 817-832.

18. Keerati-Angkoon K., Pichyangkura R. The Triple Helix Model: University-industry-governments linkage web-based application recommendation systems for emerging commercial-base research. $4^{\text {th }}$ International Conference on Computer and Technology Applications, ICCTA 2018. Istanbul, Turkey, 2018. pp. 101-105. 
19. Ob utverzhdenii pravil predostavleniya subsidiy na razvitie kooperatsii rossiyskikh obrazovatelnykh organizatsiy vysshego obrazovaniya, gosudarstvennykh nauchnykh uchrezhdeniy i organizatsiy realnogo sektora ekonomiki $v$ tselyakh realizatsii kompleksnykh proektov po sozdaniyu vysokotekhnologichnykh proizvodstv $v$ ramkakh podprogrammy "Infrastruktura nauchnoy, nauchno-tekhnicheskoy i innovatsionnoy deyatelnosti» gosudarstvennoy programmy Rossiyskoy Federatsii «Nauchno-tekhnologicheskoe razvitie Rossiyskoy Federatsii». Postanovlenie Pravitelstva Rossiyskoy Federatsii ot 09.04.2010 no. 218 (red. ot 21.06.2019) [«On the approval of the rules for provision of subsidies for development of cooperation between Russian higher education educational organizations, state scientific institutions and organizations of the real sector of the economy for implementation of complex projects for creation of high-tech industries within the framework of the subprogram «Infrastructure of scientific, technical and innovative activities» of the state program of the Russian Federation «Scientific and technological development of the Russian Federation». Decree of the Government of the Russian Federation of 09.04.2010 N 218 (as amended on 06/21/2019)]. Available at: http://p218.ru/images/2019/pp218n.pdf (accessed 10 November 2019).

20. O Federalnoy tselevoy programme «Issledovaniya i razrabotki po prioritetnym napravleniyam razvitiya nauchno-tekhnologicheskogo kompleksa Rossii na 2014-2020 gody». Postanovlenie Pravitelstva Rossiyskoy Federatsii ot 21.05.2013 no. 426 [On the Federal Target Program «Research and Development in Priority Directions for the Development of the Russian Science and Technology Complex for 2014-2020». Decree of the Government of the Russian Federation of May 21, 2013 No. 426]. Available at: http://fcpir.ru/upload/medialibrary/332/tekst-programmy.pdf (accessed 10 November 2019).

21. Nauchnoe upravlenie [Scientific Management]. Tomskiy gosudarstvenny universitet sistem upravleniya $i$ radioelektroniki. Available at: https://tusur.ru/ru/o-tusure/struktura-i-organy-upravleniya/departament-nauki-iinnovatsiy/nauchnoe-upravlenie\#otchjoty_o_nauchnoj_dejatelnosti/ (accessed 20 November 2019).

22. Innovatsionnye obrazovatelnye tekhnologii [Innovative educational technology]. Tomskiy gosudarstvenny universitet sistem upravleniya $i$ radioelektroniki. Available at: https://tusur.ru/ru/obrazovanie/innovatsionnye-obrazovatelnye-tehnologii (accessed 20 November 2019).

Received: 25 November 2019. 